\title{
UM RESGATE HISTÓRICO E FILOSÓFICO DOS ESTUDOS DE CHARLES DU FAY
}

Anabel Cardoso Raicik* Luiz 0. 0. Peduzzi **

RESUMO: Charles Du Fay, um filósofo natural do início do século XVIII, entregou-se a uma intensa busca por encontrar mecanismos que pudessem explicar certos fenômenos elétricos ainda não compreendidos na sua época. Realizando inúmeros experimentos em constante diálogo com as hipóteses desenvolvidas, ele enuncia dois princípios e "descobre" a repulsão como algo legítimo das interações elétricas. Nessa perspectiva, este artigo ressalta, além do percurso histórico desse estudioso, a relevância da análise do contexto da descoberta para que se possam compreender, com maior propriedade, a não neutralidade do estudioso, os erros que impulsionam aos acertos e os diferentes métodos de construção do conhecimento. Ademais, ressalta-se a importância de considerações históricas e filosóficas para o ensino que visa discutir, além de conceitos físicos, concepções relativas à Natureza da Ciência.

Palavras-chave: Du Fay. Experimentos. Contexto da descoberta.

\section{UN RESCATE HISTÓRICO Y FILOSÓFICO DE LOS ESTUDIOS DE CHARLES DU FAY} RESUMEN: Charles Du Fay, un filósofo natural del inicio del siglo XVIII, se entregó a una intensa búsqueda por encontrar mecanismos que pudieran explicar ciertos fenómenos eléctricos todavía no comprendidos en su época. Realizando inúmeros experimentos en constante diálogo con las hipótesis desarrolladas, él enuncia dos principios y "descubre" la repulsión como algo legítimo de las interacciones eléctricas. Bajo esta perspectiva, este artículo resalta, además del recorrido histórico de este estudioso, la relevancia del análisis del contexto de la descubierta para que se puedan comprender, con más propiedad, la no neutralidad del estudioso, los errores que impulsan a los éxitos y los distintos métodos de construcción del conocimiento. Además, se resalta la importancia de consideraciones históricas y filosóficas para la enseñanza que pretende discutir, además de conceptos físicos, concepciones relativas a la naturaleza de la ciencia.

Palabras clave: Du Fay. Experimentos. Contexto de descubierta.

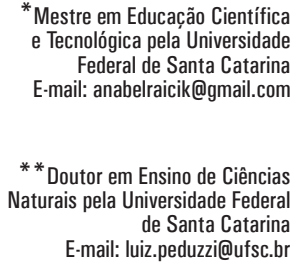

* Mestre em Educação Científica e Tecnológica pela Universidade Federal de Santa Catarina E-mail: anabelraicik@gmail.com

* * Doutor em Ensino de Ciências Naturais pela Universidade Federal de Santa Catarina E-mail: luiz.peduzzi@ufsc.br 


\begin{abstract}
A HISTORICAL RESCUE AND PHILOSOPHICAL STUDIES OF CHARLES DU FAY
ABSTRACT: Charles Du Fay, a natural philosopher of the early eighteenth century, indulged himself an intense search to find mechanisms that could explain certain electrical phenomena not yet understood in his time. Performing numerous experiments in constant dialogue with the developed hypotheses, "discovers" sets out two principles and the repulsion as something legitimate of electrical interactions. In this perspective, this article points out, beyond the historical course of this scholar, the importance of analyzing the context of discovery, more appropriately, so that they can understand the non-neutrality of the scholar, the mistakes that drive the successes and the different methods of knowledge construction. Moreover, emphasizes the importance of historical and philosophical considerations in education that discusses, in addition to physical concepts, conceptions related to Nature of Science.
\end{abstract}

Keywords: Du Fay. Experiments. Context of discovery. 


\section{INTRODUÇÃO}

Ao longo de sua pesquisa científica, Charles François de Cisternay Du Fay se deparou com situações imprevistas, com erros, com experimentos desconcertantes, e foi a partir de um árduo trabalho investigativo e exploratório que ele reconheceu a natureza da repulsão e enunciou dois princípios que conduziram a eletricidade a novos caminhos (BOSS; CALUZI, 2007). A análise de seus estudos permite evidenciar o diálogo entre seus constructos teóricos e as experimentações que desenvolveu. Contemporâneo de outros estudiosos envolvidos com pesquisas elétricas, como Hauksbee, Gray e Réaumur, Du Fay buscou encontrar regularidades nos fenômenos que já eram estudados e conferir a eles princípios gerais.

As "descobertas" " na eletricidade do início do século XVIII - como a repulsão elétrica, os dois tipos de eletricidade (vítrea e resinosa), os isolantes e os condutores, a comunicação por contato e a distância percorrida pela virtude elétrica etc. -, quando analisadas em seu contexto histórico-filosófico, permitem evidenciar a importância de aspectos subjetivos e lógicos presentes no contexto da descoberta e que são inerentes à ciência. Assim, torna-se possível discutir, a partir de Du Fay, os papéis que um experimento pode assumir na pesquisa científica. Ademais, analisar o erro, a coletividade, a importância da persistência e, sobretudo, que as observações não são neutras; elas são subsidiadas por concepções teóricas de cada estudioso.

Contudo, no ensino de ciências, a ausência de discussões de cunho histórico e filosófico, como normalmente ocorre nos manuais didáticos, pode gerar uma visão distorcida da dinamicidade científica. Equivocadamente, professores e livros didáticos, de modo geral, perpassam a imagem de que a investigação científica e a produção do conhecimento são procedimentos que envolvem aquele método científico, único e infalível (MOREIRA; OSTERMANN, 1993; KÖHNLEIN; PEDUZZI, 2002; FERNÁNDEZ et al., 2002); isento de erros, casualidades ou imprevistos. Contudo, é consenso entre os filósofos da ciência que o conhecimento não se constrói com uma sequência rígida de passos nem segue um único método científico (FORATO; PIETROCOLOA; MARTINS, 2011; GIL PÉREZ et al., 2001). Segundo Kragh (2001), foi a própria história da ciência que ensinou à crença positivista que a ciência livre de considerações valorativas e culturalmente independente é um mito; mostrou também que o método científico, entendido como uma doutrina absoluta e canonizada, é um engano.

Com o propósito de desmistificar alguns desses estereótipos, por exemplo, vem se defendendo, enfaticamente, a inserção de estudos sobre a ciência no ensino (CLOUGH; OSLON, 2008; PRAIA; GIL PÉREZ; VILCHES, 2007; EL-HANI, 2006; LEDERMAN, 2007; PEDUZZI, 2005; MCCOMAS; ALMAZROA; CLOUGH, 1998; MATTHEWS, 1995, 1998; MARTINS, 2006; HODSON, 1986). Isso, de certo modo, significa explicitar os processos de desenvolvimento científico e as influências que a ciência sofre. Ou seja, em parte, propõe-se valer-se não apenas do contexto da justificativa, evidenciando resultados prontos, 
mas discorrer sobre o contexto da descoberta. Quando essa análise é explicitada, sobretudo com o uso de episódios históricos, percebe-se que não há, e não pode haver, uma dicotomia entre esses dois contextos. Todos os elementos de um contexto estão intrinsecamente ligados ao outro. Desse modo, a repulsão elétrica só pode ser uma "descoberta" atribuída a Du Fay, por exemplo, quando se analisa a gênese dessa descoberta, ou seja, ao serem explorados a sua estrutura e os argumentos conferidos a ela. Quanto mais se pormenorizam a prática e o desenvolvimento científico, menos se percebe a separação entre os dois contextos (descoberta - justificativa) (STEINLE, 2006).

A história da eletricidade é nova se comparada com a de outras áreas do conhecimento, como a astronomia, a mecânica (ASSIS, 2011). Hoje, possuímos uma compreensão bastante razoável dos fenômenos elétricos, devido aos conceitos que foram estruturados ao longo de sua história. O entendimento da repulsão elétrica, o reconhecimento do sistema de atração-contato-repulsão e a enunciação das eletricidades vítrea e resinosa envolveram um processo rico entre as experimentações e as hipóteses desenvolvidas para compreendê-los. Comparado com o conceito de atração elétrica, o de repulsão, por exemplo, levou muito tempo até que fosse descrito e explicado como um fenômeno, de fato, de natureza elétrica.

Neste artigo, busca-se explicitar os estudos desenvolvidos por Charles Du Fay que exemplificam os distintos papéis que um experimento pode assumir na atividade científica, sobretudo os que foram realizados em um período histórico em que o quadro conceitual da eletricidade era muito incipiente e comportava diferentes explicações para um mesmo fenômeno. Ademais, permeando as "descobertas" realizadas por esse investigador, procura-se evidenciar que a estrutura das mesmas não independe de sua justificação, isto é, que uma “descoberta" é um processo complexo que envolve reconhecer a existência e a natureza de algo. Objetiva-se, igualmente, apresentar a razão para a atribuição da "descoberta" da repulsão elétrica a Du Fay, embora esse fenômeno já tivesse sido observado e estudado anteriormente. Por fim, ressalta-se a importância de considerações históricas e filosóficas no ensino que visa discutir, além de conceitos físicos, concepções relativas à Natureza da Ciência.

\section{OS CONTEXTOS DA DESCOBERTA E DA JUSTIFICATIVA}

No seu livro "Experiência e Predição”, publicado em 1938, Hans Reichenbach explicita a distinção entre o contexto da descoberta e o contexto da justificativa (DJ - contexto da Descoberta/ contexto da Justificativa). Para esse filósofo, físico e matemático, os estudos apresentados à comunidade científica e relevantes para a filosofia da ciência deveriam apresentar uma reconstrução lógica do conhecimento, que não demandava, necessariamente, uma explicitação do seu desenvolvimento. Assim, teria de haver uma significativa diferença entre 
como os trabalhos dos cientistas eram apresentados aos seus pares e a forma pela qual eles teriam sido realmente desenvolvidos.

O contexto da descoberta compreenderia os processos subjetivos da pesquisa científica (as ideias, a casualidade, os erros, os imprevistos) e deveria restringir-se ao interesse da história da ciência, da psicologia e da sociologia, disciplinas consideradas fatuais. O contexto da justificativa abrangeria uma reconstrução lógica da atividade científica; isento de aspectos "não lógicos", esse contexto deveria ser analisado pela filosofia e epistemologia da ciência, disciplinas de caráter normativo. Conforme Hoyningen-Huene (1987), essa distinção foi fundamental para Popper, Carnap, Hahn, Neurath e Whewel.

Entretanto, a partir de 1960, iniciaram-se reações a essa dicotomia, em autores como Hanson, Thomas Kuhn, Polanyi Michael e Paul Feyerabend. As críticas à distinção DJ explicitam a incoerência da separação entre a filosofia da ciência e a história na análise do procedimento científico. Nessa nova perspectiva, argumenta-se, por exemplo, que o tipo de pensamento envolvido no processo científico não difere fundamentalmente do raciocínio utilizado para a justificação; consequentemente, os contextos da descoberta e da justificativa são temporalmente indistintos. Nesse sentido, para uma análise mais pormenorizada e fidedigna do procedimento científico, alega-se que disciplinas empíricas são relevantes à epistemologia; elas podem explicitar elementos da atividade científica que possibilitam uma melhor compreensão do conhecimento e do seu desenvolvimento.

Embora a distinção entre os contextos DJ vise extinguir aspectos psicológicos e sociológicos do contexto da justificação, autores como Kuhn (2011) argumentam que esses elementos estão presentes nesse contexto, tanto na tomada de decisão e na aceitação de um novo corpo de conhecimento pela comunidade científica quanto individualmente pelos seus pares.

Outra objeção à dicotomia DJ refere-se à complexidade de uma descoberta científica. A compreensão de uma descoberta vai muito além da reconstrução lógica da investigação científica. O seu entendimento requer uma abordagem integrada entre história e filosofia da ciência, dentre outras coisas. Uma descoberta não surge de uma mera observação, de um insight ou de um palpite; ela demanda reconhecer "tanto que algo ocorre quanto o que ele é" (KUHN, 2011, p. 189). O contexto da descoberta, portanto, envolve também aspectos lógicos da pesquisa científica.

As diferentes críticas à distinção entre os contextos da descoberta e da justificativa, no âmbito de uma nova perspectiva filosófica - se comparada àquela do início do século XX -, transcendem o ponto de vista de Reichenbach (1938). Para além da distinção entre a maneira como a ciência é desenvolvida e como ela é apresentada para a comunidade, as objeções refletem uma nova postura da filosofia da ciência. Sobretudo, essa nova perspectiva visa analisar a ciência como um processo que intercala reconstruções lógicas e normativas com aspectos subjetivos presentes em seu processo. 


\section{OS ESTUDOS DE CHARLES DU FAY}

Charles François de Cisternay Dufay, um jovem tão diferente de Gray em temperamento, classe, educação [...]. Em 1733, Dufay, aos 35 [anos], era enérgico, brilhante, minucioso e ordenado, já um dos principais membros da Academia de Ciências de Paris [...]. (HEILBRON, 1979, p. 250)

Charles François de Cisternay Du Fay (1698 - 1739) nasceu em Paris em 1698. Seguiu a tradição da família que, por mais de um século, servia à Guarda Francesa. Ingressou como tenente em 1712, com apenas 14 anos, e permaneceu até 1723, quando, com a influência de sua família, candidatou-se e assumiu o cargo de químico adjunto na Academia Francesa de Ciências (HEILBRON, 1979; BOSS; CALUZI, 2007). No campo da eletricidade, suas maiores contribuições foram a distinção entre as eletricidades vítrea e resinosa, o reconhecimento do mecanismo de atração-contato-repulsão e, consequentemente, a "descoberta" da repulsão como um fenômeno genuinamente elétrico.

Sua família, influente na sociedade e com boas condições financeiras, oportunizou a ele fácil acesso à alta sociedade e à Academia. Sem experiências nos estudos científicos, Du Fay pode ter se beneficiado dessas circunstâncias sociais para alcançar, mais facilmente, o seu status. Um dos seus principais amigos, o cardeal Rohan, era um nobre e chefe eclesiástico da França. Rohan, em um momento fortuito, teria apresentado Du Fay para René Réaumur, um dos principais membros da Academia Francesa de Ciências. Isso culminou na sua aceitação como químico nessa instituição. Em resposta, Du Fay teria mencionado:

Só você [Réaumur] que, por pura bondade, teve a gentileza de notar-me apenas para levantar meu grau de honra, [e] colocar a minha falta de mérito tão longe de mim. Eu posso, no entanto, garantir-lhe que esse sinal de favor vai me incentivar a tentar produzir, com trabalho árduo, o que de outra forma não possuo e que eu não pouparei esforços para justificar sua escolha à Academia. (DU FAY apud HEILBRON, 1979, p. 251).

Sua primeira publicação, ainda em 1723, discorria sobre estudos com fósforo de mercúrio. Em 1729, foi eleito membro da Royal Society e, três anos depois, tornou-se intendente do Jardim Du Roi da França, onde trabalhou também com botânica. Foi nessa época que Du Fay teve contato com os trabalhos de Gray e Hauksbee publicados na Royal Society. Conjectura-se que o interesse de Du Fay pelos fenômenos elétricos tenha se iniciado depois que ele leu artigos acerca desse tema publicados na Philosophical Transactions (HOME, 1967; HEILBRON, 1980; BERNAL, 1969). Inclusive, em muitas de suas cartas, Du Fay se sente devedor de outros estudiosos, pela inspiração que seus trabalhos propiciaram.

Eu devo esta homenagem a esta ilustríssima corporação [Royal Society], não somente como um de seus membros, mas, neste aspecto, como um devedor dos trabalhos escritos pelo Senhor Gray e anteriormente pelo Senhor Hauksbee, ambos dessa sociedade [...]. (DU FAY, 1733/4a, p. 258) 
Em suma, Du Fay iniciou seus estudos "repetindo" sistematicamente as experiências de eletricidade desenvolvidas por outros estudiosos que, com igual interesse, buscavam compreender os intrigantes fenômenos elétricos. Cabe ressaltar que, "grosso modo, ninguém jamais repete um experimento" (HACKING, 2012, p. 331). Isto é, ao se "refazer" um experimento, sempre se busca fazê-lo de maneira diferente; um material diferente, um direcionamento interpretativo distinto.

Até o início do século XVIII, muitas características de alguns corpos peculiares à eletricidade haviam sido evidenciadas, mas as questões que nortearam as novas pesquisas e, inclusive, os trabalhos desse estudioso referiam-se, sobretudo, à natureza desses fenômenos e aos mecanismos que os norteavam (BINNIE, 2001).

\section{REPULSÃO: UM FENÔMENO GENUINAMENTE ELÉTRICO}

Um dos trabalhos mais importantes de Du Fay foi publicado em 1733/4 ª, na Philosophical Transactions, intitulado A Letter from Mons. Du Fay, F. R. S. and of the Royal Academy of Sciences at Paris, to His Grace Charles Duke of Richmond and Lenox, concerning Electricity. Translated from the French by T. S. M D. Nesse artigo, ele apresenta, sucintamente, os estudos desenvolvidos e publicados em quatro memórias - ao todo, ele publicou oito.

Na quarta memória, "Quatrième mémoire sur l'électricité: De l'attraction et répulsion des corps électriques" (DU FAY, 1733b), ele trata da atração e da repulsão entre os corpos. No início de seu relato, ele explicita a concepção que se tinha acerca da virtude elétrica: ela era considerada uma virtude geral. O fato de os corpos atraírem ou repelirem uns aos outros estava associado a uma virtude que, na época, era considerada genérica e causa de ambos os fenômenos. A atração tornava-se, assim, a característica definidora da virtude elétrica. Hauksbee, por exemplo, explicava a repulsão através da teoria dos eflúvios. Nessa perspectiva, o mesmo eflúvio atrativo seria, possivelmente, responsável pela repulsão. Niccolo Cabeo argumentava que um elétrico emitia pequenas partículas de seus poros, na forma de um eflúvio. Esse eflúvio afastava do corpo o ar de sua vizinhança e, depois de incidir sobre o ar não perturbado, rarefazendo o meio, esse ar retornava com rapidez para o elétrico.

Em geral, houve uma grande relutância em admitir a repulsão como um efeito oposto ao da atração elétrica (BONAUDI, 1993), devido às diferentes explicações dadas a esse fenômeno. Dessa forma, muitos estudiosos imaginavam que o eflúvio elétrico, responsável pela atração entre os corpos, ocasionava também, por algum mecanismo impreciso, mas prevalentemente mecânico (colisões, rebotes), o seu afastamento. Cabe ressaltar que se encontra aqui uma das grandes percepções de Du Fay: reconhecer a natureza desse fenômeno que, até aquele momento, encontrava-se obscuro.

Por fim, todas as explicações referentes à repulsão não explicitavam o seu caráter eminentemente elétrico. Por vezes, o fenômeno era interpretado apenas 
como uma repulsão "aparente” (ASSIS, 2011). Contudo, examinando com maior atenção o afastamento entre os corpos, Du Fay percebeu que ele não era um fenômeno constante; em muitos casos, depois de ter havido a atração, não havia, necessariamente, o afastamento. Este comportamento instável lhe chamou a atenção.

Inicialmente, observou que os corpos leves apenas eram repelidos por um elétrico quando aproximado de algum corpo de volume considerável.

[...] e isto me fez pensar que estes corpos tornaram-se elétricos quando aproximados do tubo, e que então eles também atraiam a penugem ou a folha de ouro, e que assim ele era ainda atraído ou pelo tubo ou pelo corpo vizinho, mas que não haveria jamais uma repulsão real. (DU FAY, 1733b, p. 457)

Todavia, uma experiência sugerida por Réaumur iria lhe mostrar que essa sua conjectura estava incorreta. O experimento consistia em aproximar um pedaço de cera da Espanha eletrizado a um pequeno monte de pó de escrever colocado na borda de uma carta (uma folha de papel ou talvez um pergaminho). Ao realizá-lo, Du Fay observou que as partículas do pó eram afastadas para fora da carta, sem que se pudesse atribuir isso a atrações de corpos vizinhos.

Por vezes, como é o caso aqui, a experimentação não tem a única função de corroborar uma hipótese ou uma teoria; ela pode (re)orientar a pesquisa científica e a busca por novas explicações. O conhecimento experimental subsidia a projeção e a construção de aparatos como, também, permite manipular e desenvolver novos fenômenos. A natureza não se mostra por si só: ela se apresenta conforme a sua interação com o estudioso que a submete a uma condição específica. (IGLESIAS, 2004). A experiência indicada por Réaumur e desenvolvida por Du Fay explicita, mais uma vez, a importância das experimentações qualitativas no âmago de uma experimentação exploratória (STEINLE, 2002), em que a evidência do jogo entre as hipóteses desenvolvidas e a experimentação é muito intensa.

Nesse momento, Du Fay constatou que a repulsão ocorria mesmo quando o arranjo de outros corpos na vizinhança havia sido modificado inteiramente. Assim, o efeito repulsivo ficou evidente; não poderia ser sustentado como uma consequência da atração. Por meio de um experimento ainda mais sensível (fig. 1), Du Fay corrobora esse resultado.

Se colocarmos folhas de ouro sobre um cristal, e aproximarmos o tubo [de vidro eletrizado] por baixo, as folhas são repelidas para cima sem cair de volta sobre o cristal, e certamente não podemos explicar este movimento pela atração de nenhum corpo vizinho. A mesma coisa acontece através da gaze colorida e de outros corpos que deixam passar o escoamento elétrico, de modo que não podemos duvidar que não houvesse ali uma repulsão real na ação dos corpos elétricos. (DU FAY, 1733b, p. 458) 
Figura 1: Umas das experiências que levou Du Fay ao reconhecimento da repulsão elétrica.

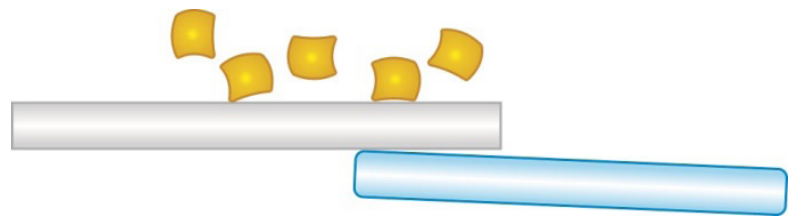

A partir dessas constatações, Du Fay atribuiu à repulsão um caráter elétrico. Nessa perspectiva, ele "descobriu” a repulsão elétrica (PEDUZZI, 2013; ASSIS, 2011; RONAN, 1983; HEILBRON, 1979; STEINLE, 2006). Ou seja, essa "descoberta" é atribuída a esse estudioso no sentido de que ele a admitiu como real e, de fato, existente. Assim, sua "descoberta" se deu pela justificativa de sua conjectura de que o afastamento entre os corpos é um evento elétrico. Como salienta Kuhn (2011), permeando o contexto da descoberta, vê-se, então, uma estrutura que não independe de sua justificação, pois "é um processo complexo, que envolve o reconhecimento tanto da existência de algo, como de sua natureza" (KUHN, 2011, p. 81). Assim, pode-se dizer que:

A justificativa da hipótese seria uma característica constitutiva dessa descoberta. O contexto da descoberta é "carregado" com o contexto da justificativa, porque "descoberta" é um termo que se refere a uma conquista epistêmica: se há sucesso em descobrir algo então, sem dúvida, esse algo existe. (ARABATZIS, 2006, p. 217)

Em sua “descoberta” da repulsão elétrica, em 1733, Du Fay já revelava uma expectativa teórica e psicológica. Ele esperava encontrar uma resposta ao afastamento de dois ou mais corpos depois de os mesmos terem se atraído, ao mesmo tempo em que precisava entender o quê e por que esse afastamento ocorria. De acordo com a classificação de Hanson (1967), essa "descoberta" é do tipo puzzle-out. Visto que muitos estudiosos já haviam observado o mesmo fenômeno, mas desenvolvido explicações que fugiam ao escopo de interações elétricas, Du Fay o reconheceu e o "descobriu", uma vez que atribuiu ao fenômeno de repulsão um caráter elétrico.

Não obstante, a atribuição dessa "descoberta" a Du Fay só se torna possível quando se analisa a gênese desse conhecimento. Somente analisando os trabalhos desse sábio e de seus pares é que se torna plausível argumentar que ele foi o descobridor da repulsão elétrica. Contudo, ainda que nomear alguém como descobridor de algo não seja o aspecto mais importante, com a história da eletricidade, é possível explorar a gênese desse conceito e, por conseguinte, analisar o momento e de que forma foi atribuída a esse fenômeno a natureza elétrica. Sem uma análise histórica adequada - subsidiada por concepções filosóficas contemporâneas, como a análise concomitante dos contextos DJ -, não seria possível conceber essa assertiva. 


\section{A ENUNCIAC̦ÃO DE DOIS PRINCÍPIOS GERAIS: O SISTEMA “ACR” E A ELETRICID- ADE VÍTREA E RESINOSA}

Com o intuito de analisar, sistematizar e encontrar um mecanismo simples que descrevesse o afastamento entre os corpos depois de ter havido atração, Du Fay refez algumas experiências já desenvolvidas por outros estudiosos - com variações nas distâncias, nos tipos de materiais, no tamanho dos corpos etc. (PEDUZZI, 2013). Dessa forma, o francês exercitou e testou seus pressupostos teóricos. Como frisam Wong e Hodson (2008), as observações não falam por si; devem ser interpretadas. Buscando sempre uma regularidade, ele observou atentamente o comportamento dos corpos utilizados em suas experimentações. Com esse procedimento, conjecturou que haveria uma relação entre os corpos que são ou não elétricos com os fenômenos de atração e repulsão. Essa constatação culminaria no seu primeiro princípio:

Enfim, tendo refletido sobre o fato de que os corpos menos elétricos seriam mais vivamente atraídos que os outros, eu imaginei que o corpo elétrico atrairia talvez aqueles que não são nem um pouco [elétricos] e afastaria todos aqueles que se tornaram elétrico pela aproximação e pela comunicação da virtude [elétrica]. (DU FAY, 1733b, p. 458)

Du Fay comenta uma experiência desenvolvida por Guericke que consiste em manter uma penugem flutuando acima de uma esfera de enxofre atritada, mas afirma que não obteve êxito em executá-la. "Esta falta de sucesso vem do fato de que a experiência não é detalhada o suficiente, ou do fato de que eu não a entendi bem" (DU FAY, 1733b, p. 458). Contudo, no artigo de 1733/4a, Du Fay comenta que efetuou esse experimento "realizando o experimento relatado por Otto de Guerik” (DU FAY, 1773/4a, p. 262). Por sua vez, Hauksbee também menciona que reproduziu essa experiência utilizando materiais mais simples. Com a configuração experimental de Hauksbee, Du Fay consegue (ou novamente consegue) realizar essa experiência. Ele esfrega um tubo de vidro para torná-lo elétrico e, segurando-o horizontalmente, deixa cair sobre ele um pedaço de folha de ouro. A partir disso, ele apura que, tão logo a folha de ouro toca o tubo, ela é repelida perpendicularmente a uma distância que varia de acordo com o seu turbilhão elétrico ${ }^{3}$ (fig. 2). Du Fay alcançou distâncias de oito e dez polegadas.

Figura 2 : Mecanismo de atração-contato-repulsão observado por Du Fay.

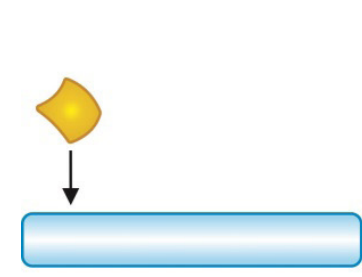

(a)

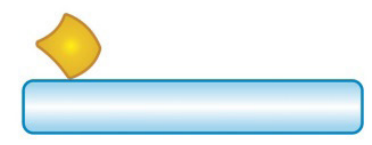

(b)

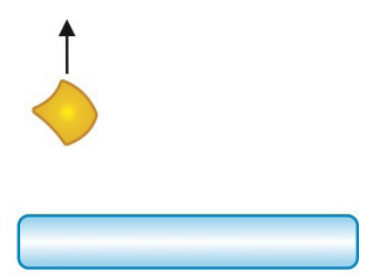

(c) 
seguinte forma:

Acentuando sua suspeita inicial, Du Fay interpreta esse fenômeno da

A explicação de todos esses fatos é bem simples, supondo o princípio que acabei de descrever; porque, na primeira experiência [fig. 2], quando se deixa cair a folha sobre o tubo [eletrizado], ele atrai fortemente esta folha que não é nem um pouco elétrica, mas assim que ela toca o tubo, ou que ela somente se aproxima dele, ela se torna elétrica, e por consequência ela é repelida, e mantém-se afastada até que o pequeno turbilhão elétrico que ela havia adquirido seja dissipado, ou pelo menos consideravelmente diminuído; não sendo mais repelida então, ela cai novamente sobre o tubo onde ela retoma um novo turbilhão [...]. (DU FAY, 1733b, p. 459-460)

Du Fay explicita outras considerações a essa experiência. "Eu traria ainda uma observação curiosa, e que traz nova luz a esta hipótese” (DU FAY, 1733b, p. 460). Ele observou que aproximando o dedo ou outro corpo qualquer de volume considerável a uma folha de ouro suspensa - depois de a mesma ter sido repelida por um tubo de vidro -, a folha era atraída imediatamente e, depois, caía sobre o tubo de vidro novamente, onde adquiria um novo turbilhão elétrico e era, então, repelida. Du Fay explica, à luz de seu primeiro princípio, que assim que a folha de ouro toca o dedo ela lhe transmite toda a sua eletricidade e, em consequência, perde toda a sua virtude elétrica, caindo, dessa forma, sobre o tubo. Ao cair, ela é atraída e adquire um novo turbilhão elétrico. Se a folha de ouro encostar no dedo uma segunda vez, ela perde novamente sua eletricidade. "Vê-se a facilidade com que estas consequências advêm do princípio que havíamos suposto, e a forma como ele clareia todas estas experiências". (DU FAY, 1733b, p. 461)

Convicto de que já estava de posse de um novo conhecimento, no artigo de 1733/4a, Du Fay explicita esse primeiro princípio da seguinte maneira:

Descobri um princípio muito simples, que explica grande parte das irregularidades e dos caprichos, se é que posso usar este termo, que parecem acompanhar a maioria dos experimentos em eletricidade. Este princípio é: corpos elétricos atraem todos aqueles que não estão desta forma, e os repelem assim que eles tornam-se elétricos, pela proximidade ou pelo contato com o corpo elétrico [...]. Ao aplicar este princípio em diversos experimentos sobre eletricidade, fiquei surpreso com o número de fatos obscuros e intrigantes que clareou. (DU FAY, 1733-4a, p. 262-263)

Assis (2011) menciona que esse primeiro princípio - comportamento regular de atração-contato-repulsão - foi considerado por Du Fay uma grande "descoberta", "e isto com razão, já que a partir deste princípio é possível compreender uma grande quantidade de fenômenos elétricos" (ASSIS, 2011, p. 75). De acordo com Heilbron (1979), que denominou essa regularidade de ACR (Atração-Contato-Repulsão), essa "descoberta" explicou muitos fenômenos "bizarros" e, até então, "incompreensíveis". Com esse princípio, houve, com ainda mais ênfase, o reconhecimento pleno da repulsão elétrica. Wheler, em 1738, publica um artigo em que comenta que já havia descoberto essa regularidade ACR no verão de 1732, mas que não havia publicado nada 
sobre o assunto (HEILBRON, 1979). Ademais, ele não sugere nenhum mecanismo para explicar essa regularidade e deixa a Du Fay a honra dessa "descoberta".

Esse primeiro princípio pode e deve ser visto no âmbito de uma "descoberta" mais universal. Foi por meio desse princípio que Du Fay constatou sua restrição: só era válido para dois corpos quando um deles tinha sido eletrizado por comunicação a partir do outro. A partir disso, enunciou o seu segundo princípio. Este outro princípio, mais abrangente, fomenta maiores interesses históricos, principalmente por sugerir a existência de duas eletricidades. Segundo Arabatzis (2006), a geração de hipóteses e a forma final da justificação de uma descoberta são processos que não precisam coincidir. A justificação em si é um processo em constante evolução, por isso são raros, ou pouco frequentes, os casos em que a justificação de uma hipótese mantém a sua forma original e primeira.

Sendo assim, esse episódio histórico exemplifica a incoerência, na perspectiva da moderna filosofia da ciência, da separação do contexto da descoberta do contexto da justificativa. Uma vez que a justificação é um processo em constante evolução, ao longo do processo da descoberta, a justificação vai sendo (re)formulada. Logo, o contexto da descoberta e o contexto da justificação são processos temporalmente indistintos; a geração de hipóteses e a proposição de teorias visam à compreensão de um fenômeno e, de modo consequente, à resolução de um determinado problema. A investigação científica abrange muitas fases, e cada qual envolve, mesmo que parcialmente, uma justificativa. Dessa forma, os contextos DJ estão entrelaçados de tal maneira que não permitem, satisfatoriamente, uma análise dicotômica.

Du Fay prossegue com novas reflexões. Observando que os corpos tornados elétricos por comunicação ou pelo contato são repelidos por aqueles que os tornaram elétricos, ele se questiona se o mesmo acontece com todos os outros corpos elétricos, qualquer que seja o seu tipo e, ainda, se os corpos elétricos só diferem entre si pelo nível de eletricidade que possuem (DU FAY, 1733b; WHITTAKER, 1910; HEILBRON, 1979).

Sustentando no ar duas folhas de ouro com um tubo de vidro eletrizado, ele percebeu que elas sempre se mantinham distantes uma da outra. Isso condizia muito bem com o seu princípio: uma vez que ambas estavam eletrizadas, deveriam se repelir (fig. 3). Contudo, o que "desconcertou prodigiosamente" Du Fay foi sua próxima experiência.

Figura 3: Experiência com duas folhas de ouro suspensas por um tubo eletrizado. A distância ("repulsão") entre as folhas evidencia a validade do primeiro princípio de Du Fay.

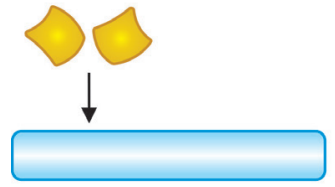

(a)

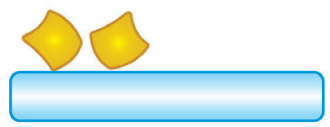

(b)

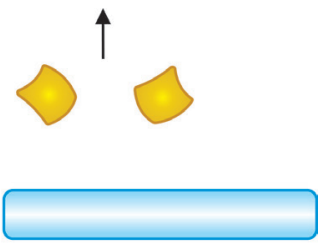

(c) 
Em síntese, Du Fay suspendeu no ar uma folha de ouro por meio de um tubo de vidro eletrizado e aproximou da folha um pedaço de goma-copal eletrizado por atrito. A folha de ouro foi imediatamente atraída pela resina (fig. 4). Ele se disse surpreso com o resultado: "Confesso que esperava um efeito totalmente contrário, porque, segundo meu raciocínio, a copal, que estava elétrica, deveria afastar a folha, que também estava" (DU FAY, 1733b, p. 464). De acordo com seu primeiro princípio, ele esperava observar uma repulsão entre os corpos, já que dois corpos elétricos se repeliriam. No entanto, apesar de refazer a experiência inúmeras vezes, o mesmo resultado acontecia, utilizando-se âmbar, ouro ou cera da Espanha.

Depois de várias tentativas que não me satisfizeram, aproximei da folha de ouro repelida pelo tubo uma bola [esfera] de cristal de rocha atritada e tornada elétrica, [e então observei que] ela repele esta folha da mesma forma que o tubo. Um outro tubo aproximado da folha afasta-a do mesmo modo, enfim eu não pude mais duvidar que o vidro e o cristal de rocha tenham feito o contrário que a goma copal, o âmbar e a cera de Espanha, de modo que a folha repelida por uns, por causa da eletricidade que ela contraiu, era atraída pelo outros; isto me fez pensar que talvez houvesse dois tipos de eletricidade diferentes [...].

(DU FAY, 1733b, p. 465)

Figura 4 : Uma folha de ouro suspensa por um tubo de vidro eletrizado foi atraída por um goma-copal também eletrizado. Essa experiência foi "desconcertante" para Du Fay, pois contrariava seu primeiro princípio. Contudo, como sempre existem contrapontos, foi essa experiência que propiciou a enunciação de outro princípio, ainda mais relevante para os estudos elétricos.

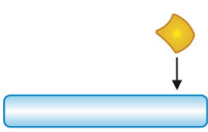

(a)

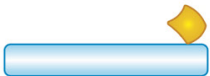

(b)

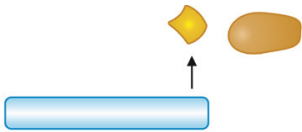

(c)

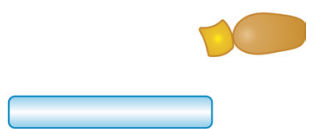

(d)

Uma das primeiras impressões de Du Fay, além da surpresa, foi refletir sobre como aquele fato havia passado despercebido, até aquele momento, pelos que se debruçavam nos estudos elétricos. Ainda, afirmou que ele mesmo tinha relutado em acreditar nessa nova característica da eletricidade, supostamente por contrariar seu primeiro princípio. A casualidade, nesse caso, levou Du Fay a se questionar sobre a validade de seu princípio anterior e para quais materiais isso poderia novamente ocorrer; "tais acidentes só encontram as pessoas que os merecem" (HANSTEEN, 1857), ou seja, quem tem pressupostos, interesses e habilidades suficientes para reconhecê-los. O "erro" constatado no primeiro princípio propiciou a Du Fay enunciar o seu segundo princípio, que, no artigo de 1733/4a, é exposto da seguinte maneira:

Por acaso lançou-se em meu caminho outro princípio, mais universal e extraordinário que o anterior, que lança uma nova luz sobre o tema eletricidade. Este princípio é: existem 
duas eletricidades distintas, muito diferentes uma da outra, uma que eu chamo de eletricidade vítrea e a outra de eletricidade resinosa. A primeira é aquela do vidro, pedra-cristal, pedra preciosa, pelo de animais, lã e muitos outros corpos. A segunda é aquela do âmbar, [resina] copal, goma-laca, seda, linha, papel, e um vasto número de outros materiais. A característica dessas duas eletricidades é que um corpo de eletricidade vítrea, por exemplo, repele todos aqueles que possuem a mesma eletricidade e, ao contrário, atrai todos aqueles de eletricidade resinosa [...]. Deste princípio podemos, com a mesma facilidade, deduzir a explicação de um grande número de outros fenômenos. É provável que esta verdade nos leve a descobertas adicionais em muitas outras coisas. (DU FAY, 1733/4a, p. 263-264).

No âmbito de uma visão de ciência considerada infalível, o erro é algo inaceitável. Contudo, como enfatiza Bachelard (2011), o erro faz parte do verdadeiro trabalho intelectual; é com a sua retificação que a ciência progride. Assim, o erro pode se manifestar (e muitas vezes o faz) como útil e positivo. "Para Bachelard, o erro tem uma função constitutiva importante na ciência, porque as verdades são sempre provisórias" (PEDUZZI, 2011). O caso de Du Fay ilustra isso. O erro constatado no primeiro princípio o levou a outra enunciação, ainda mais geral que a anterior. Segundo Lopes (1996), que faz menção a Bachelard, "o erro deixa de ser interpretado como um equívoco, uma anomalia a ser extirpada. Ou seja, com Bachelard, o erro passa a assumir uma função positiva na gênese do saber [...]". (LOPES, 1996, p. 252)

De acordo com Hanson (1967), a "descoberta" de Du Fay pode ser denominada de trip-over. Nesse tipo de "descoberta", não há um corpo teórico ainda totalmente formado referente ao fenômeno em questão. Assim, nesse episódio histórico, a experiência apresentou um resultado inesperado, que permitiu a Du Fay classificar as substâncias em dois grupos diferentes de acordo com seu comportamento. Segundo Praia, Cachapuz e Gil Perez (2002), a construção do conhecimento científico é pautada em um constante jogo entre as hipóteses que são formuladas e as expectativas lógicas ou não que se sobressaem na pesquisa desenvolvida; é "um constante vaivém entre o que pode ser e o que 'é, uma permanente discussão e argumentação/contra-argumentação entre a teoria e as observações e as experimentações realizadas" (PRAIA; CACHAPUZ; GIL PEREZ, 2002, p. 255).

É possível elucidar, com esse caso específico, a dinâmica que existe entre hipótese e experimentação no desenvolvimento do conhecimento científico. Inicialmente, Du Fay formulou uma hipótese, corroborada pela experimentação, que resultou em seu primeiro princípio. No entanto, ele se deparou com resultados inesperados quando variou os materiais, e esse processo culminou com a enunciação de outro princípio, ainda mais universal, que se tornou uma de suas grandes contribuições para o campo da eletricidade.

Nos seus estudos, Du Fay explicita o método utilizado para a identificação da espécie de eletricidade de cada corpo. Ele argumenta que basta eletrizar uma determinada substância e aproximá-la de um material já categorizado, como o vidro ou o âmbar, e analisar se os corpos se repelem ou se atraem. Em suas palavras: 
É preciso somente eletrizar uma linha de seda, que sabemos pertencer a [classe de] eletricidade resinosa, e verificar se aquele corpo eletrizado a atrai ou a repele. Se ele a atrair, certamente é da classe de eletricidade que chamo de vítrea, e se ele a repelir é da mesma classe de eletricidade da seda, que é a resinosa. (DU FAY, 1733/4a, p. 264-265)

Du Fay conclui sua quarta memória explicitando "duas novas verdades sobre esta matéria [eletricidade] e dois princípios dos quais não tínhamos até então a menor suspeita" (DU FAY, 1733/4a, p. 475). A primeira "verdade" refere-se aos corpos elétricos que, depois de atrair determinadas substâncias, só passam a repeli-las quando elas também se tornam elétricos pelo contato ou pela aproximação de ambos; assim, a repulsão é um fenômeno elétrico. A segunda refere-se às duas eletricidades distintas, a saber, a vítrea e a resinosa.

Por fim, a insistência de Du Fay em organizar, regularizar e sistematizar os fenômenos elétricos até então conhecidos, antes de se lançar às novas experimentações, enriqueceu o seu trabalho e lhe proporcionou descobrir essas "verdades" mencionadas, de grande importância para a história e o desenvolvimento da eletricidade.

\section{OUTROS ESTUDOS ELÉTRICOS}

Ainda no âmbito dos estudos elétricos, Du Fay desenvolveu inúmeros experimentos utilizando fitas de cores diferentes. Stephen Gray havia afirmado que os corpos podem atrair mais ou menos de acordo com suas cores. Isso incentivou Du Fay a verificar tal hipótese, contudo, ele se deparou com diferentes resultados. Inicialmente, Gray eletrizou diversas fitas coloridas de mesmo tamanho e mesmo peso e verificou que o verde, o azul e o violeta atraíam mais fortemente que as outras cores (BOSS; CALUZI, 2007). Em um experimento que consistia em colocar gazes de diferentes cores em cima de um arco de madeira e, sobre as gazes, folhas de ouro, Du Fay observou que a folha de ouro era atraída por todas as gazes, exceto a branca e a preta. Isso o levou a acreditar que as cores influenciavam muito a eletricidade (DU FAY, 1733/4a). No entanto, modificando seu aparato experimental, ele obteve novos e contraditórios resultados. Verificou que, aquecendo ou umedecendo as fitas coloridas, todas elas atraíam as lâminas de ouro, aparentemente em igual intensidade. Ainda explicitou que, lançando as cores de um prisma sobre uma gaze branca, esta gaze não apresentou nenhuma diferença em sua atração. "Por esta razão, a diferença não provém da cor em si, mas do material que é empregado para este fim” (DU FAY, 1733/4a, p. 260).

Na síntese de suas quatro memórias, Du Fay (1733/4a) também comenta os experimentos de Gray acerca da condução da virtude elétrica através de um garoto suspenso por linhas de seda. Du Fay pendurou a si próprio e observou, com isso, "coisas extraordinárias".

Enquanto eu estava suspenso nas linhas, se o tubo eletrizado fosse colocado próximo às minhas mãos, ou minhas pernas, e então se outra pessoa se aproximasse de mim e passas- 
se a sua mão a uma distância de aproximadamente uma polegada da minha face, pernas, mãos ou roupas, imediatamente emitiria de meu corpo uma ou mais picadas, com estalos, causados tanto na pessoa quanto em mim. Há uma pequena dor, semelhante a uma picada de alfinete ou queimadura de uma faísca, que é tão perceptível através das roupas quanto sobre a mão ou a face. No escuro estes estalos são, como pode ser facilmente imaginado, como muitas faíscas de fogo. (DU FAY, 1733/4a, p. 261-262)

Ele ainda comentou que o mesmo efeito de estalos e faíscas ocorreria com um animal vivo. Cabe salientar que Gray já havia mencionado a possibilidade de verificar a comunicação da virtude elétrica dependurando um animal, inclusive ele o fez com um pintinho vivo. Em 1735/6, Gray publicou outro artigo na Philosophical Transactions, em que apresenta sua imensa satisfação por saber que Du Fay havia refeito sua experiência e, mais do que isso, feito novas descobertas, como a do efeito luminoso. "Isso me traz uma satisfação que não é pequena, que minhas descobertas elétricas foram não apenas confirmadas por um filósofo [natural] tão sábio como o Sr. Du Fay, mas que ele tenha feito várias novas descobertas" (GRAY, 1735/6, p. 17). No fim de sua síntese, Du Fay explicita a importância dos trabalhos de Gray para as suas descobertas e não reluta em admitir que foi a partir dos trabalhos desse estudioso (de outros investigadores e de vários trabalhos, como apresenta em diferentes momentos nas suas publicações) que se inclinou para os estudos elétricos.

Imploro a Vossa Alteza [Charles, Duque de Richmond e Lenox] para comunicá-la a Royal Society e, em particular para o senhor Gray, que trabalha neste tema com muita aplicação e sucesso, para quem reconheço minha dívida pelas descobertas que fiz e também por aquelas que poderei fazer futuramente, visto que é dos escritos dele que eu tomei a decisão de dedicar-me a este tipo de experimento. (DU FAY, 1733/4a, p. 265-266)

Em mais um momento da história, verificam-se a cooperação e a coletividade, evidenciadas por meio de cartas e do diálogo direto entre os estudiosos, que se fazem presentes na atividade científica e norteiam o desenvolvimento científico. Essa característica está cada vez mais presente na física atual, globalizada e marcada pela construção de redes de cooperação que trabalham para além dos limites territoriais, políticos, acadêmicos.

\section{CONSIDERAC̣ÕES SOBRE OS TRABALHOS DE DU FAY: IMPLICAC̣ÕES PARA O ENSINO}

Os estudos de Du Fay, especificamente a "descoberta" da repulsão elétrica e a enunciação de seus dois princípios, propiciam marcantes considerações epistemológicas, filosóficas e históricas para o ensino de ciências. Sobretudo, permitem ressaltar a complexidade do contexto da descoberta e alguns dos elementos subjetivos pertencentes e inerentes à ciência. A experimentação exploratória (STEINLE, 1997, 2002), que possibilita objetar a dicotomia entre os contextos da 
descoberta e da justificativa, está presente em seus estudos. Du Fay estava imerso em um momento histórico no qual inexistia um corpo teórico científico bem-definido para os conceitos - considerados hoje triviais quando não analisados em seu contexto histórico (ASSIS, 2011). Os seus estudos, com evidente pluralidade metodológica, foram conduzidos por aspirações epistêmicas de "descobrir", entender, compreender ou, ainda, pelo anseio de alcançar regularidades empíricas elementares. Entretanto, uma maneira de especificar tal tipo de experimentação é estudar suas características por meio de uma análise dos pormenores da construção e da prática científica, concomitantemente aos contextos da descoberta e da justificativa. Dessa forma, torna-se possível compreender melhor a construção da ciência e analisá-la no âmbito da sua gênese e da sua validação.

Muitos estudiosos antes de Du Fay haviam observado o afastamento entre os corpos depois da sua atração. Contudo, a observação de um fenômeno não presume uma "descoberta". Descobrir requer argumentação, na qual é preciso dispor-se a querer entender o fenômeno e explicá-lo. Ainda assim, muitos livros didáticos, quando apresentam uma "descoberta" científica, normalmente não a contextualizam. No caso específico da repulsão elétrica, ao discorrerem sobre o assunto, os livros abordam o seu descobridor como sendo aquele que observou e registrou o fenômeno; não fazem menção às distintas interpretações que permearam as explicações desse fenômeno até Du Fay (RAICIK; PEDUZZI, 2013). Sobretudo, sem uma contextualização adequada, uma "descoberta" não passa de um simples ato de lampejo. Quando, ao se discutir a "descoberta" da repulsão elétrica, atribui-se a Du Fay essa conquista, rompe-se com a concepção de “descoberta" como sinônimo de observação ou vice-versa. Argumentando-se e contextualizando-se uma determinada "descoberta", como a da repulsão, evidenciam-se a estrutura conceitual e epistemológica desse contexto e a complexidade envolvida em uma investigação científica.

Percebe-se nos estudos de Du Fay o quanto ele se fez valer dos questionamentos e das problematizações. Com a repulsão entre os corpos foi assim. Ele iniciou seus estudos especificamente nessa área por perceber que esse afastamento não possuía uma regularidade. Assim, buscou um mecanismo que pudesse favorecer esse afastamento e, sobretudo, procurou e ansiou por uma explicação mais plausível que aquela que se tinha para a repulsão entre os corpos. Permeando o contexto da descoberta, vê-se, então, uma estrutura que não independe de sua justificação; trata-se, como evidencia Kuhn (2011), de um processo complexo que envolve reconhecer a existência e a natureza de algo. A indicação experimental de Reaumur a Du Fay exemplifica esse vínculo; a partir da comunicação e da divulgação de seus estudos, Du Fay redireciona e dá novos rumos à sua pesquisa, reconhecendo o conceito e interpretando o fenômeno da repulsão elétrica.

O segundo princípio de Du Fay - ainda que "questionável”, já que atualmente se sabe que materiais podem carregar-se positiva ou negativamente, dependendo do material com os quais são atritados - é importante tanto do ponto de vista histórico, por propiciar novos desenvolvimentos conceituais no campo da eletricida- 
de, quanto do didático. Suas discussões mostram que mesmo ideias, hipóteses e experiências "simples" a princípio são valiosas quando devidamente contextualizadas e analisadas.

Os estudos de Du Fay podem também contraexemplificar algumas imagens problemáticas da natureza da ciência, como a empírico-indutivista; a individualista e elitista; a aproblemática e a-histórica; e a rígida - algorítmica, exata, infalível (GIL PÉREZ et al. 2001). Esse notável exemplar histórico desmistifica um dos grandes estereótipos da ciência: que ela é uma verdade permanente e inquestionável!

A enunciação do segundo princípio foi propiciada pelo "erro" constatado no primeiro. Esse, por sua vez, foi fruto de uma casualidade. Ao modificar as configurações de suas experiências, Du Fay percebeu que um dos fenômenos contradizia sua premissa. Dois corpos elétricos foram atraídos ao invés de se repelirem, conforme, nessa perspectiva, deveria ocorrer. Contudo, como já foi mencionado, uma casualidade (ou um acidente) pode se tornar digna de atenção e propiciar novas investigações científicas, desde que percebida como tal. Assim, apenas uma mente propensa e imersa em determinados assuntos estaria apta para determinadas "descobertas" a partir de um acaso. Como enfatizam Kipnis (2005) e Hanson (1967), um acaso possui suas complexidades, e seus pormenores devem ser explicitados. Dessa forma, os autores caracterizam a relevância lógica em um evento casual e a importância da análise dos muitos fatores envolvidos na prática científica para a compreensão plena de um acaso - como, por exemplo, a inserção do estudioso em determinado contexto teórico interligado à casualidade ou ainda a expectativa ou não daquele acaso.

Por fim, a explicitação de que há concomitância do contexto da descoberta com o contexto da justificativa viabiliza uma análise mais aprofundada do procedimento científico e, por conseguinte, dos fatores que o influenciam. Com isso, torna-se admissível analisar-se a estrutura envolvida em uma "descoberta" científica - e, consequentemente, extinguir a noção de "observou-se, logo se descobriu que" -, o que demonstra a necessidade de combinar discussões históricas e filosóficas no âmbito didático; "toda opção didática à história da ciência tem um embricamento inevitável com a filosofia da ciência" (PEDUZZI, 1998, p. 55). A explicitação da gênese do conhecimento, do processo do desenvolvimento científico e de alguns percalços da ciência permite que se explore o real papel do experimento nas pesquisas científicas; nem sempre ele serve para corroborar ou refutar uma teoria. Esses são alguns dos aspectos da natureza da ciência que não podem ficar ausentes da sala de aula, sob pena de o ensino de física se tornar uma tarefa de memorização de fórmulas sem significado, sem reflexão sobre o sentido e a importância da ciência na vida moderna, altamente tecnológica.

\section{NOTAS}

${ }^{1}$ Descobrir é muito mais do que uma mera observação ou um insight. A descoberta de algo é um processo complexo, que envolve o reconhecimento de sua existência e de sua natureza. Há vários tipos de descobertas científicas, cada qual, com determinada estrutura conceitual. Uma 
discussão pormenorizada sobre este assunto pode ser encontrada, por exemplo, em Hanson (1967) e Raicik e Peduzzi (2015).

2“A Inglaterra utilizou o calendário juliano até 1752; dessa forma, até 1752 o ano-novo inglês começava em 25 de março. Entretanto, 'grande parte da Europa já havia adotado o calendário gregoriano'. Por isso, para citar datas até o dia 25 de março utilizava-se uma indicação de ano que contemplava os dois calendários, na qual colocavam-se dois números para expressar o último dígito, como 1707/8. $\mathrm{O}$ primeiro número indicava $\mathrm{o}$ ano no calendário juliano e o segundo indicava $\mathrm{o}$ ano no calendário gregoriano. Após 25 de março utilizava-se somente o ano comum a ambos os calendários". (BOSS; ASSIS; CALUZI, 2012, p. 26)

${ }^{3}$ Turbilhão elétrico: equivalente à virtude elétrica; qualidade elétrica.

\section{REFERÊNCIAS}

ARABATZIS, T. On the Inextricability on the context of Discovery and the context of justification. Revisiting Discovery and Justification, v. 14, p. 215-230, 2006.

ASSIS, A. K. T. Os fundamentos experimentais e bistóricos da eletricidade. São Paulo: Livraria da Física, 2011.

BACHELARD, G. A formação do espirito cientifico: contribuição para uma psicanálise do conhecimento. Rio de Janeiro: Contraponto, 2011.

BERNAL, J. D. Science in History. Volume 2: The Scientific and Industrial Revolutions. Penguin Books, 1969.

BINNIE, A. Using the History of Electricity and Magnetism to Enhance Teaching. Science \& Education, v. 10, p. 379-389, 2001.

BONAUDI, F. Groping in the dark: magnetism and electricity form prehistory to (almost) Maxwell. Nuclear Physics B-Proceedings Supplements, v. 33, n. 3, p. 8-20, 1993.

BOSS, S. L. B; ASSIS, K. T. A.; CALUZZI, J. J. Stephen Gray e a descoberta dos condutores e isolantes: tradução comentada de seus artigos sobre eletricidade e reprodução de seus principais experimentos. São Paulo: Cultura Acadêmica, 2012.

BOSS, S. L. B.; CALUZI, J. J. Os conceitos de eletricidade vítrea e eletricidade resinosa segundo Du Fay. Revista Brasileira de Ensino de Física, v. 29, n. 4, p. 635-644, 2007.

CLOUGH, M. O.; OSLON, J. K. Teaching and assessing the nature of science: An Introduction. Science \& Education, v. 17, p.143-145, 2008.

DU FAY, F. R. S. A letter from mons. Du Fay, F. R. S. and of the Royal Academy of Sciences at Paris, to His Grace Charles Duke of Richmond and Lenox, concerning Electricity. Translated from the French by T. S. M D. Philosophical Transactions, v. 38, p. 258-266, 1733/4a.

. Quatriéme mémoire sur l'électricité. De l'attraction et répulsion des corps électriques. Tradução Livre: Rafaela Rejane Samagaia. Mémoires de l'Académie Royale des Sciences, p. 457-476, 1733b.

EL-HANI, C. N. Notas sobre o ensino de história e filosofia das ciências na educação científica de nível superior. In: SILVA, C. C. (Org.). História e Filosofia da Ciência no Ensino de Ciências: Da Teoria à Sala de Aula. São Paulo: Editora Livraria da Física. p. 3-21, 2006.

FERNÁNDEZ, I et al. Visiones Deformadas de La Ciencia Transmitidas por la Enseñanza. Enseñanza de las ciencias, 2002. p. 477-488.

FORATO, T. C. M.; PIETROCOLOA, M.; MARTINS, R. A. Historiografia e natureza da ciência na sala de aula. Caderno Brasileiro de Ensino de Física, v. 28, n. 1, p. 27-59, 2011.

GIL PÉREZ, D. et al. Para uma imagem não deformada do trabalho científico. Ciência \& Educação, v. 7 , n. 2, p. 125-153, 2001. 
GRAY, S. Experiments and Observations upon the Light That is Produced by Communicating Electrical Atrraction to Animal or Inanimate Bodies, Together with Some of its Most Surprising Effects; Communicated in a Letter from Mr. Stephen Gray, F. R. S. to Cromwell Mortimer, M. D. R. S. Secr. Pbilosopbical Transactions, v. 39, p. 16-24, 1735/6.

HACKING, I. Representar e Intervir: tópicos introdutórios de filosofia da ciência natural. Rio de Janeiro: EdUERJ, 2012.

HANSON, N. R. An Anatomy of Discovery. The Journal of Philosophy, v. 64, n. 11, p. 321-352, 1967.

HANSTEEN, Ch.: 1857, 'Letter to Faraday, December 30, 1857'. In: Jones, B. (ed.), The Life and Letters of Faraday, London, 1870.

HEILBRON, J. L. Electricity in the 17th \& 18th Centuries. Berkeley: University of California Press, 1979.

. Experimental natural philosophy. In: ROUSSEAU, G. S.; PORTER, R. (ed.), The Ferment Knowledge: Studies in the Historiography of Eighteenth-Century Science, Cambridge University Press, 1980.

HODSON, D. Philosophy of Science and Science Education. Journal of Philosophy of Education, v. 20, n. 2, p. 215-225, 1986.

HOME, R. W. Francis Hauksbee's theory of electricity. Archive for history of exact sciences, v. 4, n. 3, p. 203-217, 1967.

HOYNINGEN-HUENE, P. Context of Discovery end Context $\mathrm{f}$ Justification. Studies in History and Philosophy of Science, v. 18, n. 4, p. 501-515, 1987.

IGLESIAS, M. El giro hacia la práctica en filosofía de la ciencia: una nueva perspectiva de la actividad experimental. Opción, n. 20, v. 44, p. 98-119, 2004.

KIPNIS, N. Chance in Science: the discovery of Electromagnetism by H.C. Oersted. Science \& Education, v. 14, p. 1-28, 2005.

KÖHNLEIN, J. F. K.; PEDUZZI, L. O. Q. Sobre a concepção empirista-indutivista no ensino de ciências. In: ENCONTRO NACIONAL DE PESQUISA EM ENSINO DE FÍSICA, 8., Águas de Lindoia-SP, 2002. Atas do VIII Encontro de Pesquisa em Ensino de Física, 2002.

KRAGH, H. Introdução à historiografia da Ciência. Tradução de Carlos Grifo Babo. Porto: Porto, 2001.

KUHN, T. S. A estrutura das revoluções científicas. São Paulo: Perspectiva, 2011.

LEDERMAN, N. G. Nature of science: past, present, and future. In: ABELL, S. K.; LEDERMAN, N. G. (Eds.). Handbook of research on science education. Mahwah, NJ: Lawrence Erlbaum Associates, p. 831-880, 2007.

LOPES, A. R. C. Bachelard: o filósofo da desilusão. Caderno Brasileiro de Ensino de Física, v.13, n.3, p. 248-273, 1996.

MARTINS, R. A. Introdução: história da ciência e seu uso na educação. In: SILVA, C. C. (Org.). Estudos de história e filosofia das ciências: subsidios para aplicação no ensino. São Paulo: Editora Livraria da Física, 2006.

MATTHEWS, M. R. História, filosofia, e ensino de ciências: a tendência atual de reaproximação. Caderno Catarinense de Ensino de Física, v. 12, n. 3, p. 164-214, 1995.

. In Defense of Modest Goals When Teaching about the Nature of Science. Journal of Research in Science Teaching, vol. 35, n. 2, p. 161-174, 1998.

McCOMAS, W, F.; ALMAZROA, H.; CLOUGH, M. The nature of science in science education: in introduction. Science \& Education, v. 7, p. 511-532, 1998.

MOREIRA, A. M.; OSTERMANN, F. Sobre o ensino do método científico. Caderno Catarinense de Ensino de Física, v.10, n. 2, p. 108-117, 1993.

PEDUZZI, L. O. Q. As concepções espontâneas, a resolução de problemas e a História e a Filosofia da Ciência em um curso de Mecânica. 1998. 850p. Tese (Doutorado em Educação) - Centro de Ciências da Educação, Universidade Federal de Santa Catarina, Florianópolis.

. Sobre a utilização didática da História da Ciência. In: PIETROCOLA, M. (org.). Ensino de física: conteúdo, metodologia e epistemologia numa concepșão integradora. Florianópolis: Editora da UFSC, 2005. 
. Evolução dos Conceitos da Física. 1. ed. Florianópolis: UFSC/EAD/CED/CFM, 2011. 130 p. (ISBN: 978-85-99379-92-9).

. Do efeito âmbar à garrafa de Leyden. Florianópolis: 2013. (versão preliminar, publicação interna).

PRAIA, J.; CACHAPUZ, A.; GIL PEREZ, D. A hipótese e a experiência científica em educação em ciência: contributos para uma reorientação epistemológica. Ciência \& Educação, v. 8, n. 2, p.253262, 2002.

PRAIA, J.; GIL PÉREZ, D.; VILCHES, A. O papel da natureza da ciência na educação para a cidadania. Ciência \& Educação, v. 13, n. 2, p. 141-156, 2007.

RAICIK, A. C.; PEDUZZI, L. O. Q. Uma análise da terminologia descoberta e sua contextualização nos livros didáticos: os estudos de Gray e Du Fay. In: ENCONTRO ESTADUAL DE ENSINO DE FÍSICA, 5. Porto Alegre (RS). Atas... 2013.

. A estrutura conceitual e epistemológica de uma descoberta científica: reflexões para o ensino de ciências. Caderno Brasileiro de Ensino de Física, v. 32, n. 1, 2015. No prelo.

REICHENBACH, H. Experience and Prediction. Chicago: University of Chicago Press, 1938.

RONAN, Colin A. História ilustrada da ciência da Universidade de Cambridge. Jorge Zahar Editor, 1983.

STEINLE, F. Entering new fields: exploratory uses of experimentation. Philosophy of Science, v. 64, p. 565-574, 1997.

. Experiments in History and Philosophy of Science. Perspectives on Science, v. 10, n. 4, p. 408432, 2002.

. Concept formation and the limits of justification: "Discovering" the two electricities. Revisiting Discovery and Justification, p. 183-195, 2006.

WHITTAKER, E. T. A bistory of the theories of aether and electricity: from the age of Descartes to the close of the Nineteenth Century. Londres: Longmans, Green and CO., 1910.

WONG, S. L.; HODSON, D. From the Horse's Mouth: What scientists Say About Scientific Investigation and Scientific Knowledge. Science Education, Wiley Periodicals, p. 109-130, 2008.

Data de recebimento: 09/07/2014

Data de Aprovação: 19/01/2015

Data de Versão Final: 15/02/2015

Contato:

Anabel Cardoso Raicik

Campus Reitor João David Ferreira Lima, s/n - Trindade, Florianópolis - SC, Brasil - 88040-900

Email: anabelraicik@gmail.com 